\title{
Social discrimination in community forestry: Socio-economic and gender perspectives
}

\author{
R. Parajuli ${ }^{1}$, R.K. Pokharel ${ }^{2}$ and D. Lamichhane ${ }^{3}$
}

\begin{abstract}
A study was carried out to analyze the existing social discrimination among Community Forest User Group (CFUG) members. Two CFUGs representing heterogeneous ethnic groups in Syangja district were selected to examine the participation of CFUG members in Community Forestry (CF) activities, benefit sharing and fund mobilization system. PRA/RRA tools like questionnaire survey, wealth ranking, key informant survey, triangulation, and informal discussion were employed to generate primary data. Statistical parameters such as percentage, mean, ANOVA, and contingency coefficient were used to interpret this data. The perception of local people was measured on the five point Likert scale, and Chi-square test was applied to interpret this result. The participation of the poor, disadvantaged group and women were minimal in CF activities but their presence was more at the time of forest product distribution. Timber had been distributed less to the poor and disadvantaged group (DAG) households than to others. More than 65\% CFUG members were unaware about CFUG fund. Their overall perceptions of CF management were not positive. The result clearly demonstrated discrimination between the rich and the poor, male and female, and DAG and non-DAG within the CFUG.
\end{abstract}

Key words: Community forest user group, discrimination, participation, disadvantaged group, poor

C ommunity forestry (CF) of Nepal has been acknowledged as a successful, innovative and truly community-oriented programme (Acharya, 1999; Pokharel, 2004). It has been perceived as the most effective strategy for restoring and managing forest resources. CF was introduced with the aim of fulfilling the subsistence need for forest products among the rural people, and for controlling the deforestation in the country (Adhikari, 1990).

However, CF is criticized for failing to address the needs of women, low caste and poorer segments of society who are the real users of forest (Hobley, 1991; Baral, 1993; Graner, 1997; Timsina, 2001). A study conducted by Kanel and Subedi (2004) suggested that the contribution of $\mathrm{CF}$ towards supporting the poorest, most vulnerable and marginalized members of society had been limited. Similarly a number of studies such as Gentle (2000), and Kandel and Niraula (2004) concluded that the distribution of the forest products was inequitable and the interests of poor and disadvantaged groups (DAGs) had not been properly addressed while management decisions were made.

Decision making in most communities is skewed in favour of men, as women are culturally restricted i.e. they are often not allowed to be involved in decision making by their families. The poor, disadvantaged and socially marginalized groups were often ignored or excluded from participating in decision-making in most communities (Gilmour and Fisher, 1991; Baral, 1993; Graner, 1997). These groups were too preoccupied in just earning their livelihood.

A number of studies has shown that elite members of the society tend to occupy all the key positions of the executive committee and to make decisions regarding harvest, product distribution and mobilization of fund (Baral and Subedi, 1999). The ordinary members of the group were hardly involved in the overall process and had virtually no idea about

\footnotetext{
Louisiana State University, Baton Rouge, LA, USA. Email: rparaj1@1su.edu

Professor, Tribhuvan University, Institute of Forestry, Pokhara.

District Forest Office, Jumla.
} 
harvest and the financial matters of their Community Forest User Group (CFUG) (Nightingale, 2002).

By contrast, in a study from Kabhrepalanchok and Lalitpur district, Sharma (2003) suggested that distribution of forest products system in community forestry had no any discrimination on the basis of wealth or caste. The current system of CF in Nepal has helped in developing a mechanism for social cohesiveness among the forest users of different castes/ethnic groups, and helped to minimize the gap between high and low castes (Acharya and Oli, 2004). Likewise, Pokharel (2004) also claimed that $\mathrm{CF}$ had become a vehicle for ushering in changes in the social processes to empower the poor and DAG members of the community. In this context, it is relevant to evaluate empirically how CF benefits are allocated among the different socioeconomic strata of the population and how far the poor and DAG segments of the population were receiving benefits from this programme. Such studies would help further development of the policies of forest management as a means to support the livelihoods of the rural poor and contribute to the reduction of discrimination between rich and poor, high and low caste people. The general objective of this study is, therefore, to assess the social discrimination in terms of social, economic and gender perspectives in different CF programmes. The specific objectives are: to document the different activities that are undertaken by CFUG; to examine the participation of CFUG members in CF related activities; and to uncover the benefit sharing and fund mobilization mechanism among CFUG members.

\section{Methods}

The research was carried out in two selected CFUGs of Syangja district. After discussing with DFO staff and reviewing CFUG records in DFO, Sahanle CFUG and Aahale Masaswara CFUG were selected for study sites. The Sahanle CFUG is located in ward numbers 2 and 3 of Arjun Chaupari VDC under Arjun Chaupari Range Post. The forest was divided into four blocks for scientific management. The forest area of 16 ha was dominated by Katus (Castanopsis indica)-Chilaune (Schima wallichi) forest.

Aahale Masaswara CFUG is situated in Putali Bazaar Municipality- 12 of Syangja district. The total number of households was 156 and the forest area was 50 ha. The CFUG was economically and ethnically heterogeneous with Damai, Newar, Magar, Chhetri.
Valuable Sal and Salla were the dominant species in this CF.

Both qualitative and quantitative research techniques were employed to collect the data. Different PRA/ RRA tools such as participatory wealth ranking, discussion with committee members, key informants survey and semi-structured questionnaire survey were used to generate the primary data. A total 61 households $(20 \%)$ were selected from two CFUGs through stratified random sampling based on participatory wealth ranking. The questionnaire was pre-tested and some necessary changes were made before conducting the household interview. Secondary data relevant to the study were collected from relevant sources like CFUGs, DFO, Institute of Forestry (IOF) library and various published and unpublished literature. Operational plan (OP) and the book of CFUG Meeting minutes were also reviewed during discussions with the committees.

This data was analyzed with qualitative and quantitative techniques. Most of the interpretations were based on the categorization of respondents (Table 1). The data was fed into the SPSS 11.5 and MS- Excel computer software programmes to generate different statistical parameters such as percentage, mean, ANOVA and graphical displays, for both qualitative and quantitative data interpretation. The perception of respondents were measured along 'a strongly agree to strongly disagree (1-5)' Likert Scale format. Pearson Chi square tested the difference in the perception of the respondents according to their social, economic and gender status. Other parameters such as correlation coefficient, contingency coefficient, one way ANOVA were carried out to find the relationship and association among the variables.

\section{Results and discussion}

\section{CFUG activities}

All CFUGs are legally required to have and function by its own constitution and OP. The OP elaborates the forest inventory of the CF and its overall technical management. In reality, however, neither of the CFUGs studied had followed their OPs for most of their activities. These activities are discussed below:

\section{Forest management activities}

Forest management activities include plantation, tending operations and forest protection. In both CFUGs, plantation was done with the participation 
Table 1: Analytical categories

\begin{tabular}{lllc}
\hline Categories of respondents & \multicolumn{3}{l}{ Analytical Categories } \\
\hline Social & NDAG & DAG & - \\
Economic & Rich & Medium & Poor \\
Gender & Male & Female & - \\
\hline
\end{tabular}

of CFUG members. Seedlings were provided by Syangja District Forest Office. Tending operations including cleaning, thinning (mainly 3D: dead, dying and diseased trees) and pruning generated fuelwood. Heralu (forest guard) was hired for protection of forest in both CFUGs. To protect forest from fire, fire lines were cleared every year. The planted species were: Dalbergia sissoo, Pinus roxburgbii, Michelia species, Artocarpus lakoocha, Thysanolaena maxima for enrichment planting in Aahale CF, and Artocarpus lakoocha, Alnus nepalensis, Prunus cerasoides in open eroded area of Sahanle CF.

\section{Forest product collection and distribution system}

Firewood and timber for house construction were the main forest products provided to all CFUG members. One member of each household had to be involved voluntarily for firewood collection. The distribution system in both CFUGs was on equal basis. Though OP had prescribed the annual allowable harvest (AAH) from forest, committee (mainly key members) determined the quantity for each household.

\section{Income generation activities}

Both CFUGs had different income generation activities such as NTFP management, nursery preparation, and special programmes for the poor, DAGs and women, and these were clearly stated in their OPs. But they had not implemented any such programmes in practice although Aahale CFUG professed interest in such programmes.

\section{Participation of CFUG members in different meetings}

In principle, every member of a CFUG should participate in the meetings organized by the CFUG. They have equal right to speak and participate in the decision making process. But in both CFUGs studied, the participation of the poor, DAG and women was less than the rich, male and NDAG members.

In both CFUGs, only one general meeting had been organized to pass the OP and constitution. Only $22 \%$ DAGs, $7 \%$ poor and $32 \%$ female respondents had attended the meeting. They had not actively participated in the meeting, since most were unaware about the contents of the OP and the constitution.

Table 2: Different activities conducted by CFUG

\begin{tabular}{|c|c|c|c|}
\hline \multirow[t]{2}{*}{ Activities } & \multicolumn{2}{|c|}{ CFUG } & \multirow[t]{2}{*}{ Remarks } \\
\hline & Aahale & Sahanle & \\
\hline 1. Plantation & Yes & Yes & Once \\
\hline 2. Silvicultural operations & Yes & Yes & Yearly \\
\hline 3. Forest protection by guard & Yes & Yes & Since beginning \\
\hline 4. Fire line construction & Yes* & No & \\
\hline 5. Fuelwood, Timber distribution & Yes & Yes & Yearly \\
\hline 6. Community development activities & Yes** & No & \\
\hline 7. Income generation activities & No*** & No*** & \\
\hline
\end{tabular}

* Yearly, ${ }^{* *}$ as per required for local people, ${ }^{* * *}$ but described in OP

\section{Community development activities}

Community development includes trail construction, gabion wall construction, drinking water, and micro hydro-electricity works. Aahale CFUG had already conducted such activities. The committee decides the activities that are to be undertaken in a particular year. However, in Sahanle, no such community development activities had been conducted yet. The committee only focused on the protection of forest rather than distributing benefits to the community.
Chi-square test confirmed that attendance of respondents differed significantly with social as well as economic conditions of respondents (Table 3).

Likewise, in the meeting convened to form the FUC, only $16 \%$ DAG, $14 \%$ poor and $36 \%$ female had participated. Due to their lower participation, they were generally ignored and not included in Forest User Committees (FUC). Even when included in the FUC, they did not express their views. Nightingale 
Table 3: Participation in the meeting when OP and constitution was finalized

\begin{tabular}{|c|c|c|c|c|c|c|c|}
\hline \multirow{9}{*}{$\begin{array}{l}\text { Participation } \\
\text { in the } \\
\text { meetings when } \\
\text { OP and } \\
\text { Constitution } \\
\text { was finalized }\end{array}$} & \multicolumn{2}{|c|}{ Status of respondent } & \multicolumn{2}{|c|}{$\begin{array}{c}\text { Attendance of respondents } \\
(\%)\end{array}$} & \multirow[t]{2}{*}{ df } & \multirow[t]{2}{*}{$\begin{array}{l}\chi^{2} \\
\text { value }\end{array}$} & \multirow[t]{2}{*}{ Sig. } \\
\hline & & & Yes & No & & & \\
\hline & & $\mathrm{DAG}$ & 22.2 & 77.8 & 1 & 3.14 & * \\
\hline & Social & NDAG & 46.5 & 53.5 & & & \\
\hline & & Rich & 60.7 & 39.3 & 2 & 11.92 & $*$ \\
\hline & Economic & Medium & 31.6 & 68.4 & & & \\
\hline & & Poor & 7.1 & 92.9 & & & \\
\hline & & Male & 42.9 & 57.1 & 1 & 0.697 & $* *$ \\
\hline & Gender & Female & 31.6 & 68.4 & & & \\
\hline
\end{tabular}

* Significant at $95 \%$ confidence interval, ** not significant

(2001) also attributed the low participation of women and DAG in decision-making processes as a major reason for their being ignored.

\section{Participation in general assembly}

In both CFUGs, the general assembly had been called once a year, prior to the tending operations to collect firewood. Most of the women members of the CFUG get involved in the general assembly because it has direct effect on forest products collection. Despite their greater participation in such programmes, most of the DAGs and women did not feel free to express their opinions. The minute books of both CFUGs revealed that more females $(58 \%)$ had participated in Aahale CFUG and there was satisfactory attendance of DAGs also (Table 4). But in case of Sahanle CFUG, only 16\% of DAGs and $31 \%$ of female had attended the general assembly of 2061 B. S (2004 AD).

From the informal discussions, it was also learned that women and DAG had not taken part in the discussion although they were present in the meeting. They felt compelled to attend the general assembly because they were concerned about their access to forest products. These discussions also underscored how highly dependent the poor, DAGs, and mainly women were on CF for fulfillment of the requirements for forest products.

\section{Participation in Forest User Committee}

In both CFUGs, participation of DAG, women and poor members was minimal in the committee and they never occupied key positions. They only served as general members. The same individuals have been holding the key posts since the hand over. In Aahale Masaswara CFUC, only two women of two DAG families were involved in present 15-member CFUC (Fig 1). How can two persons represent more than
Table 4: Attendance of members in 2061 (2004 AD) CFUG general assembly

\begin{tabular}{lcccc}
\hline \multirow{2}{*}{$\begin{array}{l}\text { Respondent's } \\
\text { Status }\end{array}$} & \multicolumn{2}{c}{ Aahale CFUG } & \multicolumn{2}{c}{ Sahanle CFUG } \\
\cline { 2 - 5 } & Count & \% & Count & \% \\
\hline DAG & 37 & 3 & 16 & 16 \\
NDAG & 58 & 61 & 73 & 74 \\
Male & 40 & 42 & 68 & 69 \\
Female & 55 & 58 & 31 & 31 \\
\hline
\end{tabular}

Source: Minute book of CFUG (2005)

60 households of DAGs? In reporting a similar situation, Poudel (2003) concluded that presence of women and DAG member in committee was only for attendance and not for discussion, suggestion and decision making.

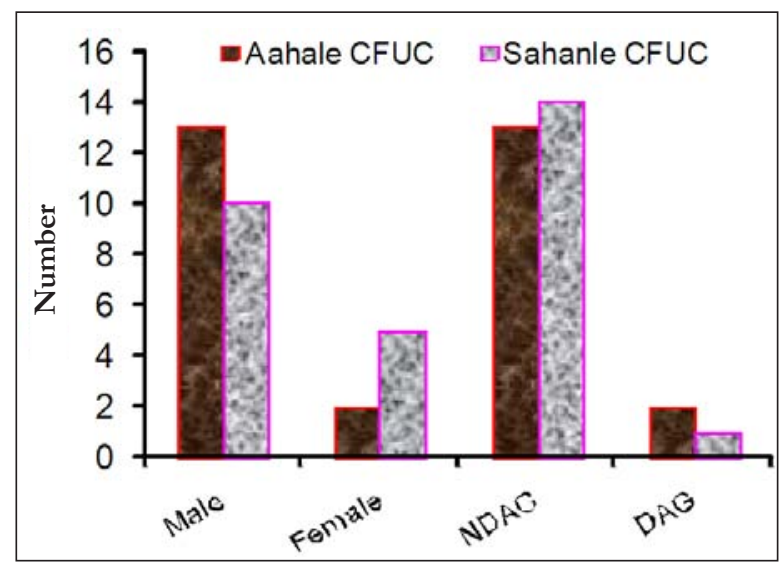

Fig 1: Composition of present CFUC

The same case was reported in Sahanle CFUG; only one DAG and five female members were incorporated in the 15-member CFUC. There was no co-ordination among the committee members so committee meetings were irregular and inactive. DAGs and women believed that only the educated and experienced persons could contribute to the committee so they hesitated to participate in CFUC. As the representation of the poor and DAGs in the 
executive committee was meager, the sharing mechanism could hardly fulfill the demands of forest products for the poor and DAGs (Kanel and Kandel, 2004). of each household had to be involved voluntarily in this operation.

Table 5: Participation in training, workshop and study tours

\begin{tabular}{|c|c|c|c|c|c|c|c|c|c|}
\hline \multirow[t]{3}{*}{ Statement } & \multicolumn{2}{|c|}{ Status of respondent } & \multicolumn{4}{|c|}{ Response ( $\%)$} & \multirow{3}{*}{ df } & \multirow{3}{*}{$\begin{array}{l}\chi^{2} \\
\text { value }\end{array}$} & \multirow{3}{*}{ Sig. } \\
\hline & & & \multirow{2}{*}{$\begin{array}{l}\text { Never } \\
\text { attended }\end{array}$} & \multicolumn{3}{|c|}{ Attended } & & & \\
\hline & & & & Once & Twice & $>$ Twice & & & \\
\hline \multirow{8}{*}{$\begin{array}{l}\text { Have you } \\
\text { ever attended } \\
\text { in any } \\
\text { training, } \\
\text { workshop? }\end{array}$} & \multirow{3}{*}{ Social } & $\mathrm{DAG}$ & 83.2 & 5.6 & 5.6 & 5.6 & 3 & 8.34 & * \\
\hline & & NDAG & 44.2 & 34.9 & 11.6 & 9.3 & & & \\
\hline & & Rich & 46.4 & 7.2 & 14.3 & 32.1 & 6 & 5.31 & ** \\
\hline & \multirow[t]{3}{*}{ Economic } & Medium & 57.9 & 26.3 & 10.5 & 5.3 & & & \\
\hline & & Poor & 71.4 & 14.3 & 14.3 & 0.0 & & & \\
\hline & & Male & 52.4 & 23.8 & 14.3 & 9.5 & 3 & 3.57 & ** \\
\hline & Gender & Female & 63.2 & 31.6 & 0.00 & 5.3 & & & \\
\hline & Total & & 55.7 & 26.2 & 9.8 & 8.2 & & & \\
\hline
\end{tabular}

* Significant at $95 \%$ confidence interval, ** not significant

Participation in training, workshops and study tours

About $44 \%$ of the respondents had attended CF related training, workshops and study tours. Among them, $56 \%$ were rich, followed by medium (30\%) and poor (14\%). Most of the respondents had participated in at least one such event. Similarly, 89\% of the NDAGs and only 11\% DAG respondents had attended such events. The Chi-square test also confirmed that the difference between DAGs and NDAGs members who attended the training and tours (Table 5) was statistically significant .

\section{Forest product sale and distribution system}

In both CFUGs, firewood and timber for house construction were the main products available to all CFUG members. All the forest products were distributed only among the CFUG. The forest was opened for only one week in a year (Poush/Magh or December/ January) for firewood collection and grass cutting. Silvicultural operations (cleaning, thinning, pruning, 3D removal) were the main sources for firewood. In both CFUGs, one member
In Aahale Masashwara CFUG, every member was allowed to get only 4 Bita (10 Bhari) firewood at the rate of Rs. 5 per Bita (1 Bhari= $35 \mathrm{~kg})$. In the case of timber, those people whose houses were to be constructed or renovated got timber. Most of the DAG and poor members complained that the price for timber was too high for them. There was also a provision of providing firewood for special purposes like weddings and funerals. But in Sahanle, only 3 Bita (8 Bhari) were allowed for each household. The quantity of timber was provided in a number of trees basis, so price was fixed per tree. Most of the DAG and poor respondents $(50 \%)$ stated that they had not got timber for their house construction because of the high cost of timber. As explained by (Malla et al., 2003), there is equal distribution system, but wealthier households tend to benefit more in terms of the quantity of products they obtained from CF.

Table 6 depicts the average timber distribution to different status of CFUG members. Respondents were asked how much timber they had obtained since the handing over of CF. DAG households had

Table 6: Timber distribution to CFUG members from beginning of CF

\begin{tabular}{llcl}
\hline Status of respondents & & $\begin{array}{l}\text { Average timber } \\
\text { collection in cft. }\end{array}$ & $\begin{array}{l}\text { Test statistics } \\
\text { (One way ANOVA) }\end{array}$ \\
\hline Social status & NDAG & 11.93 & f- value $=17.25^{*}, \mathrm{df}=1,59 ;$ \\
& DAG & 5.44 & Sig. .000 \\
\hline Economic status & Rich & 11.57 & \\
& Medium & 10.74 & f-value $=4.41 *, \mathrm{df}=2,58 ;$ \\
& Poor & 5.93 & Sig. .016 \\
\hline
\end{tabular}

Source: Field survey, 2005 
received an average of $5.44 \mathrm{cft}$ per household since the beginning of CF, whereas NDAG had collected $11.93 \mathrm{cft}$. Likewise, the rich and medium class people had obtained more timber than the poor members (Table 6). One way ANOVA test confirmed that timber flow to the rich and NDAG members was significantly different for the poor and DAG members in both study CFUGs.

\section{Perception of respondents on "product sale and distribution system is participatory"}

Poor and DAG respondents disagreed with the statement "product sale and distribution system is participatory" (mean value $>3.5$ ). They pointed that the elite and rich committee members had made all the decisions relating to timber distribution and providing only to those who could pay money fast. The rich and NDAG respondents had a neutral view on the statement (Table 7). The Chi-square test demonstrated that perception on this statement differed significantly with social as well as economic conditions of respondents. the following forest and community development works with their funds.

\section{Forest development works}

Poor and DAG members of CFUG were assigned priority for wage works such as:

- Annual fire line clearance

- Plantations

- Wall fencing in forest boundary

- Salary to Heralu Rs.1200 per month

(Note: they have no record of how much money had been spent in such works but committee agreed that such amount was less than $25 \%$ of the total income)

\section{Community development works}

Most of the CFUG income had been spent in community development works in Aahale CFUG. They had conducted such works in different toles (neighbourhoods) considering which programme was highly demanded by CFUG members (Fig 2).

Table 7: Perception on whether product sale and distribution system are participatory

\begin{tabular}{|c|c|c|c|c|c|c|c|c|c|c|}
\hline \multirow{3}{*}{ Variable } & \multirow{3}{*}{ Category } & \multicolumn{5}{|c|}{ Response in $\%$ within category } & \multirow{3}{*}{ Mean } & \multirow{3}{*}{$\mathrm{df}$} & \multirow{3}{*}{$\begin{array}{c}\chi^{2} \\
\text { value }\end{array}$} & \multirow{3}{*}{ Sig. } \\
\hline & & \multicolumn{2}{|c|}{ Strongly agree } & \multicolumn{3}{|c|}{ Strongly disagree } & & & & \\
\hline & & 1 & 2 & 3 & 4 & 5 & & & & \\
\hline \multirow[t]{2}{*}{ Social status } & NDAG & 16.3 & 32.6 & 32.6 & 16.3 & 2.2 & 2.56 & 4 & 9.86 & * \\
\hline & $\mathrm{DAG}$ & 5.6 & 11.1 & 38.9 & 22.2 & 22.2 & 3.44 & & & \\
\hline Economic & Rich & 21.4 & 35.7 & 32.1 & 10.7 & 0.0 & 2.32 & 8 & 16.64 & * \\
\hline \multirow[t]{2}{*}{ Status } & Medium & 10.5 & 21.1 & 36.8 & 26.3 & 5.3 & 2.95 & & & \\
\hline & Poor & 0.0 & 14.3 & 35.7 & 21.4 & 28.6 & 3.64 & & & \\
\hline \multirow{2}{*}{$\begin{array}{l}\text { Gender } \\
\text { Status }\end{array}$} & Male & 11.9 & 23.8 & 33.3 & 21.4 & 9.6 & 2.93 & 4 & 1.65 & ** \\
\hline & Female & 15.8 & 31.6 & 36.8 & 10.5 & 5.3 & 2.58 & & & \\
\hline Total & & 13.1 & 26.2 & 34.5 & 18.0 & 8.2 & 2.82 & & & \\
\hline
\end{tabular}

$1=$ strongly agree, $2=$ agree, $3=$ neutral, $4=$ disagree, $5=$ strongly disagree

* Significant at $95 \%$ confidence interval, $* *$ not significant

\section{Fund mobilization}

The major sources for fund raising in both CFUGs were forest products sale, levying fines, penalties and new membership fee. Aahale CFUG had around Rs. 22, 000 (US\$300) in its bank account while Sahanle had about Rs. 40, 000 (US\$ 540) in its bank account (from audit report, 2005). Although OP prescribed that $25 \%$ of CFUG income had to be allocated for forest development works, neither CFUGs had adhered to such rules.

In Aahale CFUG, CFUG fund was utilized for different forest as well as community development works. The committee deliberated on all decisions about fund mobilization. This CFUG had conducted depicted that Aahale CFUG had different community development activities conducted from beginning to now.

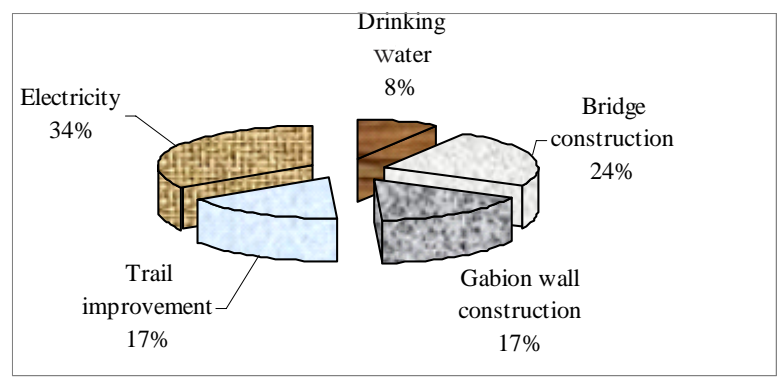

Fig 2: Fund mobilization in Aahale CFUG 
Sahanle CFUG had not spent their funds on any forest or community development works except the salary to Heralu (Rs. 1,100 per month). They were only concerned with collecting rather than mobilizing the fund.

Although both CFUGs in their OP had planned different Income Generation Activities (IGAs) for the poor, DAG and women empowerment by providing loans, such activities had not materialized. The committees hesitated to disburse loans to poor and DAGs since they believed it would be difficult to get it back. Only $34 \%$ of total respondents were aware about their CFUG fund that too not the exact amount. Only $17 \%$ DAG and $14 \%$ poor respondents had known about CFUG fund (Table 8). In Aahale CFUG, most of the DAG respondents were not satisfied with fund mobilization. Most of the poor DAG respondents were interested in getting loans from their own CF fund for different income generation activities. One female respondent from DAG household asserted that "We have drinking water problem here but the committee is working for road construction. We want drinking water first'. Chi-square value for independence test confirmed that there was significant difference between the response of DAG and NDAGs about the fund of their CF account. poor members in the committee and the passive role in the assembly suggests that the decisions were not likely to benefit the poor and DAGs. Although the CFUGs were supposed to follow the equal distribution policy for forest products, the rich and NDAG members were receiving more benefits from CF. Most of the poor and DAG respondents disagreed with current products sale and distribution system as the rule and the price allocated for the sale of forest products was not reasonable.

The CFUG fund and its mobilization were mostly controlled by NDAG and rich committee members. Almost all DAG, poor and women (65\%) respondents were unaware about their $\mathrm{CF}$ fund and where it was deposited. Even though the OP prescribed special incentives, the poor, women and DAG individuals had little access to CFUG funds and their mobilization. Most of the fund was invested on the salaries for Heralu, allowances and infrastructure development, while investment in forest development and income-generating activities were low. Present CF practice in the study area was less favorable to the livelihoods of the poor and marginalized sections of the community. There exists discrimination among the CFUG members from social and economic perspectives, but less disparity has been recorded from gender point of view.

Table 8: Perception of respondents on CFUG fund

\begin{tabular}{|c|c|c|c|c|c|c|c|}
\hline \multirow[t]{2}{*}{ Statement } & \multirow[t]{2}{*}{ Status of } & \multirow[t]{2}{*}{ respondent } & \multicolumn{2}{|c|}{ Response (\%) } & \multirow[t]{2}{*}{$\mathrm{df}$} & \multirow[t]{2}{*}{$\chi^{2}$ value } & \multirow[t]{2}{*}{ Sig. } \\
\hline & & & Yes & No & & & \\
\hline \multirow{7}{*}{$\begin{array}{l}\text { Do you know the } \\
\text { deposited amount } \\
\text { of CFUG fund? }\end{array}$} & Social & DAG & 16.7 & 83.3 & 1 & 3.85 & * \\
\hline & & NDAG & 41.9 & 58.1 & & & \\
\hline & & Rich & 42.9 & 57.1 & 2 & 3.45 & $* *$ \\
\hline & Economic & Medium & 36.8 & 63.2 & & & \\
\hline & & Poor & 14.3 & 85.7 & & & \\
\hline & Gender & Male & 38.1 & 61.9 & 1 & 0.85 & $* *$ \\
\hline & & Female & 26.3 & 73.7 & & & \\
\hline
\end{tabular}

*Significant at $95 \%$ confidence interval, $* *$ not significant

\section{Conclusion}

In both CFUGs, most activities were protection oriented rather than oriented towards other forest management or community development. Aahale CFUG had conducted some community development activities but no any such activities had been conducted in Sahanle CFUG. The rich and NDAG male members had captured most of the key positions of user committee as well as the opportunities for allowances and empowerment related activities such as trainings, workshops and study tours. The nominal presence of DAGs and

\section{Acknowledgement}

The first author would like to express sincere gratitude to ComForM/Local Danida Fellowship for providing financial support to carry out this study for the partial fulfillment of his Bachelor's degree in Forestry. 


\section{References}

Acharya, K.P. 1999. Community forestry in Nepal: a model of common property resource management. Banko Janakari 9 (2): 36-39.

Acharya, K.P. and Oli, B.N. 2004. Impacts of CF in rural livelihoods: a case study from Bharkhore CF, Parbat district. Banko Janakari 14 (1): 46-50.

Adhikari, J. 1990. Is community forestry a new concept? An analysis of the past and present policies affecting forest management in Nepal. Society and Natural Resources 3 (3): 257-265.

Baral, J.C. and Subedi, B.R. 1999. Is community forestry of Nepal's Terai in right direction ?Banko Janakari 9 (2): 20-24.

Baral, N. 1993. Where is our CF? Banko Janakari 4 (1): 12-15.

Gentle, P. 2000. The Flow and Distribution of Community Forestry Benefits: A Case Study from Pyuthan District, Nepal. M.Sc Forestry Research Thesis, University of Canterbury, Christchurch, New Zealand.

Gilmour, D.A. and Fisher, R.J. 1991. Villagers, Forests and Foresters: The Philosophy, Process and Practice of Community Forestry in Nepal. Sahayogi Press, Kathmandu, Nepal.

\section{Graner, E. 1997. The Political Ecology of} Community Forestry in Nepal. Printshop, Frensdorf, Germany.

Hobley, M. 1991. From passive to active participatory forestry: Nepal. In Projects with People: The Practice of Participation in Rural Development (ed.) Oakley, P. International Labour Office, Geneva, Switzerland.
Kanel, B.R. and Subedi, R. 2004. Pro-poor community forestry: some initiatives from the field. In Twenty-five Years of Community Forestry: Contributing to Millennium Development Goals (eds.) Kanel, K.R., Mathema, P., Kandel, B.R., Niraula, D.R., Sharma, A.R. and Gautam, M. Proceedings of the fourth national workshop on community forestry, 4-6 August 2004, Kathmandu, Nepal, 229-237.

Kanel, K.R. and Kandel, B.R. 2004. Community forestry in Nepal: achievements and challenges. Journal of Forest and Livelihood 4 (1): 55-63.

Malla, Y.B.; Neupane, H.B. and Branney, P.J. 2003. Why are not poor people benefiting more from community forestry. Journal of Forest and Livelihood 3 (1):78-90.

Nightingale, A. J. 2002. Participating or just sitting in? The dynamics of gender and caste in community forestry. Journal of Forest and Livelihood 2 (1): 17-24.

Pokharel, B.K. 2004. Contribution of community forestry to people's livelihoods and forest ustainability: experience from Nepal. www.wrm.org.uy. Access date: $15^{\text {th }}$ Jan. 2006.

Poudel, B.S. 2003. The Rural Poor and the Forest Resources: Socioeconomic Heterogeneity, Benefit Sharing and Participation in Community Forest in Nepal. M.Sc Thesis. Tribhuvan University, Institute of Forestry, Pokhara, Nepal.

Sharma, A.R. 2003. Community forestry from wealth and caste perspective. Banko Janakari 13 (1): 39-42.

Timsina, N. 2001. Empowerment or marginalization: A debate on community Forestry in Nepal. Journal of Forest and Livelihood 2 (1): 27-33 